\title{
Alteridade, gênero, sexualidade, afeto
}

O objetivo deste debate, iniciando as comemorações dos 20 anos dos Cadernos Pagu, é estimular a realização de novas reflexões sobre as articulações entre gênero, sexualidade e afetos. Levando em conta experiências de pesquisa com comunidades indígenas, ribeirinhas, quilombolas, extrativistas, populações "rurais" e com integrantes de camadas baixas urbanas, propomos uma discussão sobre a vigência e fertilidade em termos analíticos e políticos, de categorias frequentemente imaginadas como próprias de camadas médias urbanas, brancas ou "Ocidentais".

Parte significativa dos estudos antropológicos sobre sexualidade no Brasil está orientada pela hipótese foucaultiana da "sexualidade" como dispositivo de gestão do Ocidente burguês moderno (e na reelaboração de Judith Butler para pensar corpo e gênero), como criação histórica e geograficamente situada que, no país, teria marcado as camadas médias urbanas. Nesse mapa, as ditas "sociedades tradicionais" - $e$ os setores sociais considerados por alguns autores como próximos delas - oferecem um campo privilegiado para pensar a "sexualidade", na medida em que sugeririam caminhos paralelos ou divergentes dos modelos frequentemente associados a populações "urbanas e de camadas médias" (muitas vezes, implicitamente consideradas brancas). Tomando como referência esses universos de pesquisa, perguntamo-nos sobre a utilização de categorias como "sexualidade" ou "erotismo" na descrição e conexão de práticas em contextos nos quais tais categorias podem não existir ou não coincidir com as chaves teóricas que até certo ponto as produziram. Quais são os aspectos que conduzem ao pesquisador a incluir ou excluir práticas, gestos, palavras, discursos ou performances em categorias como sexualidade ou amor? Existem noções êmicas análogas, comparáveis, e qual é o seu rastro? Que lugar ocupam, ou podem ocupar, questões como 
Debate alteridade, gênero, sexualidade, afeto

homossexualidades e homoafetividades, sexo comercial, transformações corporais, alterações nos códigos de gênero, no prazer sexual, nos estudos realizados na chave do parentesco, da política local, ou de outros problemas clássicos dos estudos antropológicos voltados para as sociedades "tradicionais"?

As articulações entre gênero e sexualidade colocam outros desafios. No que se refere a gênero, as análises antropológicas têm mostrado como essa categoria foi historicamente produzida no âmbito do pensamento feminista, gestada como ferramenta analítica que, centrada na análise da posição subordinada das mulheres, contribuísse para a transformação social. A vasta produção realizada posteriormente propôs leituras mais amplas, em termos dos fluxos de relações diferenciadas de poder, que deslocaram o olhar dos "termos da relação" (homem e mulher), refletindo sobre a produção desses termos e das relações entre eles, nas performatividades e nos trânsitos entre diversas noções de masculinidade e feminilidade. Os trabalhos de Marilyn Strathern e da filósofa e crítica literária Judith Butler foram pioneiros nesse sentido.

Paralelamente, a capilarização dos discursos e efeitos das ações dos movimentos em prol dos direitos humanos e de agências de desenvolvimento atingem as "comunidades tradicionais", convertendo algumas dinâmicas marcadas por gênero e práticas sexuais em aspectos negativos, e, às vezes, criminalizados (a interseção de gênero, geração e etnia é um exemplo privilegiado, se pensarmos nas relações sexuais, conjugais e reprodutivas intergeneracionais em comunidades indígenas). A convergência entre esses movimentos teóricos e políticos torna mais complexas as análises sobre as articulações entre gênero e sexualidade e suscita uma série de questões. Como os estudos sobre "sociedades tradicionais", incluindo as análises etnológicas, tratam dos efeitos do poder no gênero, na sexualidade e nas relações entre ambos? Como esses efeitos são considerados nos estudos sobre "contato", principalmente quando aparecem no mapa grandes projetos de infraestrutura em 
territórios indígenas, ribeirinhos, extrativistas? Como as pautas dos movimentos de direitos humanos e as exigências dos programas de desenvolvimento são apropriadas ou reelaboradas, ou como podem sê-lo, em contextos percebidos como de significativa alteridade cultural? Como evitar relativismos que diluam o potencial político de "gênero" sem repetir o viés evolucionista que emparelha "tradicional" com "desigual" e "moderno" com "equitativo"? Afinal, gênero é, ou pode ser, uma categoria fértil quando estudamos "comunidades tradicionais"?

Os estudos antropológicos sobre as articulações entre sexualidade, gênero e afetos, particularmente quando se trata de "amor romântico", têm privilegiado camadas médias de grupos urbanos. A relativamente menor atenção concedida a essas articulações quando se trata de grupos ditos "tradicionais", "rurais", "marginais" suscita algumas perguntas. Esse aparente silêncio estaria vinculado a razões "êmicas", de organização do campo acadêmico e/ou a considerações políticas? Há nesses grupos discursos consolidados sobre diferentes estilos ou modalidades de afetos, incluindo ou não o "amor romântico"? Como neles se entretecem os afetos nas práticas e instituições através das quais se produz localmente o mundo (o casamento, a guerra, a política, a natureza, o comércio, as pessoas)?

A partir dessas premissas e indagações, convidamos diversas/os autores/as a realizar um posicionamento sucinto sobre alguma das perguntas ou sobre o conjunto delas, baseado nas suas experiências de pesquisa ou na reflexão em torno à produção sobre esses universos. Observamos que para sua generosa participação, as/os colaboradoras/es não tiveram acesso prévio aos textos das/dos demais participantes. No entanto, as (sugestivas) diferenças nas leituras, perspectivas e abordagens oferecem elementos para colocar em debate as articulações entre gênero, sexualidade e afetos. 